\title{
Progressive effects of nigella sativa ogaiast the interaction of sodium nitrite and sun - set yellow in albino rats
}

\author{
Eman G.E. Helal * Samir A.M. Zaahkouk ** and \\ Somaia Z. A. Rashed *** \\ *Faculty of Science, Zoology Dept., Ahzar University (Girls) \\ ** Faculty of Science, Zoology Dept., Ahzar University \\ *** Faculty of Science, Zoology Dept., Tanta University
}

\begin{abstract}
It has been noticed that kids usually eat and drink food containing food preservator and food colorants at the same time. This behavior has been attracted the attention to study the interaction between one of food preservatives ( sodium nitrite NaNO3) and one of bood colorants (sunset -yellow S.S.Yellow). The interaction of the limited dose of these two components resulted in a lethal dose. So, $1 / 10$ of this dose was used for 30 days and left for another 15 days post the last dose for recovery. Other group was supplemented with Nigella sativa ( N.S) oil in addition to the same mixture.

Ingestion of $\left(\mathrm{NaNO}_{3}\right.$ and S.S.Yellow) mixture significantly decreased rat's body weight, $\mathrm{RBC}$ and $\mathrm{WBC}$ counts, $\mathrm{Hb} \%$, $\mathrm{Hct} \%$, serum inorganic phosphorus, serum protein and serum albumin. Significant increases were observed in serum glucose, $\mathrm{T}_{3}$, $\mathrm{T}_{4}$, calcium, $\gamma$-GT, LDH, CPK, Alk.ph and cholesterol. Also cholesterol of brain, liver and heart were significantly elevated. No changes were recorded for; organ/body weight, respiratory rate, heart beats, rectal temperature, acid phosphatase activity, AST and ALT activities of serum and tissues, protein of tissues, serum globulin, and total lipids of serum and tissues, cholesterol of muscle and kidney and serum triglyarides.

A complete recovery of most biochemical and haematological parameters was observed days after stoppage of the mixture or after administration of Nigella sativa oil.

This study ringe bells of dangerous. The study showed also that even the permitted colourants and food preservatives when taken together or if taken in excessive quantity may be harmful. Therefore, provision should be made for quantities estimation of food additives in various food stuff.
\end{abstract}

\section{Introduction}

Food additives are substances intentio nally added to food. They may be naturally occurring or synthetic (Harris, 1986). The principle classes of food additives are coloring agents, preserv atives, flavours, emulsifiers and stabil izers (Lindsay, 1985). The principle preservatives are nitrites which used as salts or free acids (HMSO, 1987). The use of sodium nitrite as a preservative is common in many cooked meats, sausages and bacon and milk used for some cheeses and pizzas. The percentage of nitrite content of the daily food rations is higher than admissible level (Bilczuk et al., 1991). Apparently very little nitrites are formed by endogenous synthesis and most, if not all are of dietary origin (Bartholonew and Hill, 1984). 
Food colorants may often be considered simply cosmetic in nature, but the role they play in our food supply is actually very significant. Colour is the first sensory quality by which foods are judged, and food quality and flavor are closely associated with color. Consumers are conditioned to expect food of certain colors and to reject any deviation from their expectations (Amerine et al., 1965).

The seed essential oil of the spice and medicinal plant Nigella sativa (N.S) exhibits; hypotensive, bronchodilator and immuno potentiating properties (AlHader et al., 1993), antibacterial, antiinflammatory and analgesic activities (Khanna et al., 1993). Thymoquinone (the active principle of N.S) containing Fatty acids, exhibit antitumor activities against Ehrlich ascites carcinoma, Dalton lymphomia sarcoma cells (Salomi et al., 1992) and inhibiting factor for the chemical carcinogensis (Salomi et al., 1991). The pharmacy ological properties of N.S oil support its traditional use as a treatment of rheumatism and inflammatory diseases (Houghton et al., 1995).

Helal (2001) noticed that children often eat foods contain preservators and at the same time drink some drinks contain colorant. The questions arise here what happen when the food preservator and colorant react with each other. She mixed a limited dose of sodium nitrite (one of the most favorite preservators) with a limited dose of Sunset yellow (one of the most attractive colorants) and tested it on rats. The interaction of both limited dose gave a new compound with a lethal dose that led to the death of all rats used. So, this study was planned to use N.S oil ( one of the most important antioxidants) as antidote and to illustrate if it could ameliorate the expected hazards.

\section{Materials and Methods}

Male albino rats $(70-80 \mathrm{~g}$ body weight) were used in this study. Animals were housed in stainless steel cages rat fed and offered water ad libium. The animals were divided into three groups of 10 rats each, as follows: The $1^{\text {st }}$ group served as control group. The second group was received $10 \mathrm{mg}$ $\mathrm{NaNO}_{3} / \mathrm{kg}$ b.wt and $0.5 \mathrm{mg}$ Sunsetyellow (S.S.Yellow) daily for a month. The third group received the same dose of $\mathrm{NaNO}_{3}$ and S.S.Yellow in addition to $100 \mathrm{mg}$ of N.Sativa oil/Kg b.wt. All treated doses were given orally for each rat.

Body weights, respiration rate, heart beat rates and rectal temperature were recorded once a week through the experimental period. After 30 days of treatment, five animals of each group were decapitated, while the rest of them were kept for two weeks, without any additional treatment for recovery.

At the end of the trial, the animals were weighed and killed by decapit ation. Livers, brains, kidneys, hearts and testes were separated, cleaned from adherent tissues and weighed atonce. Pieces of liver, skeletal muscle, kidney, heart and brain were weighed and put in an appropriate amount of $30 \%$ potassium hydroxide for total protein determination. Another pieces were put in concentrated sulfuric acid for total lipid determination.

Blood samples were collected for hematological and biochemical param eters. Ethylene Diamine Tetra acetic acid (EDTA), an anticoagulant, was added to blood for hematological parameters, while blood samples for biochemical parameters were centrifu ged for $10 \mathrm{~min}$. at $5000 \mathrm{rpm}$ and supernatant sera were separated for analysis without storage or delay. Hemoglobin concentration was determined according to Van-Kampen 
\& Zulstra (1961). Red and white blood cells were counted according to the method of Rodak (1995), and haema tocrit values (Hct\%) were estimated using the technique of Rodak (1995). The biochemical analyses were carried out on the blood sera.

Glucose determination was based on the enzymatic method described by Siest \& Schielf (1981). Total proteins were estimated using the Biuret method as described by Doumas (1975). Total lipids were determined according to the method of Knight et al. (1972). Albumin was evaluated according to the method of Webester (1977), while serum cholesterol was determined as mentioned by Fossati and Medici (1987). Aspartate transaminase (AST) and alanine transaminase (ALT) activi ties were accomplished using the method of Reitman and Frankel (1975). Gamma-glutamyl transpeptidase was estimated by the method of Meister $e t$ al. (1981). While, lactic dehydrogenase (LDH) activity was determined accor ding to Raabo (1963).Creatine phosph okinase (CPK) assay was performed using Sigma chemical company reagent kits (St. Louis M).

Triglycerides were determined by the method of Rojkin et al. (1974). Alkaline phosphatase activity was mea sured according to the method of Belfield and Goldberg (1971). And the activity of plasma acid phosphatase was determined according to the methods of Tietz (1986).

Inorganic phosphorus was deter mined according to the method of Fiske and Subbarow (1925) and serum calcium $\left(\mathrm{Ca}^{++}\right)$concentration was estimated according to the method adopted by Ray Sarkar and Chauhan (1967). Thyroid hormones (T3\&T4) assay were determined by using he enzyme-linked immunosorbent assay (ELISA) (Whitley et al., 1996).
For comparison of different expe rimental animal groups, the student ttest was used. Significant differences between the means of control and treated groups were considered only at $\mathrm{P}<0.05$ (Sokal and Rohife, 1981).

\section{Results}

Control young rats showed an increase $(19.6 \%$ and $18.9 \%)$ in body weight after the treatment and recovery periods respectively, while mixture $\left(\mathrm{NaNO}_{3}\right.$ and S.S.Yellow) supplement ation resulted in a significant reduction $(\mathrm{P}<0.01)$ of the body weight gain during the two periods. On the other hand, body weight loss was evident $(\mathrm{P}<$ $0.01)$ in rats treated with the mixture $\left(\mathrm{NaNO}_{3}\right.$ and S.S.Yellow), which followed by body weight gain after the recovery period (Table 1 ).

The relative weight of organs $(\%$ of organ body weight ) of treated and control rats after both treatment and recovery periods are presented in table (1). No detectable changes in the relative weight of the kidney, brain, heart, liver and testes were recorded in all treated groups throughout the experimental period.All of the animals showed insignificant changes in rectal temperature, respiratory rates and heart beats after both treated and recovery periods (Table ,2).Investigation of the effect of oral administration of $\mathrm{NaNo} 3$ and S.S. yellow on various haemato logical indices of rat's red blood cells revealed highly significant decrease $(\mathrm{P}<$ 0.01) after the treated period, while supplementation with N.S induced insignificant change in the red blood count. After the recovery period, no significant change was recorded in all treated groups (Table,3). Investigation of other haematological indices revealed that treatment with the mixture caused significant reduction in; white blood cells count, blood haemoglobin 
concentration and. haematocrite value throughout the experimental period. On the other hand, rats treated with N.S showed insignificant changes of all blood indices for the period of treatment as well as the recovery period (Table 3 ).

As expected, the both treated rats showed a highly significant increase $(\mathrm{P}<0.01)$ in glucose level compared with the control ones. While, N.S treated rats had insignificant change in serum glucose level after both treatment and recovery periods in comparison with the control rats as shown in table (4).

A significant increase in the level of both $\mathrm{T}_{3}$ and $\mathrm{T}_{4}$ was observed in rats received NaNo3 and S.S.yellow comparing to the control rats, after both treated and recovery periods. These levels were lower than the normal in the group received both the additives and N.Sativa as shown in table (4).

There was significant increase in serum concentration of calcium $(\mathrm{P}<0.01)$ in the group treated with $\mathrm{NaNO}_{3}+$ S.S.Yellow after both treatment and recovery periods. However, insignificant changes were recorded in the group treated with food addition and N.Sativa throughout the experimental period. On the other hand, a significant decrease $(\mathrm{P}<0.01)$ was recorded in serum phophorus level in all treated groups after 30 days of treatment. While, the group treated with $\mathrm{NaNO}_{3}+$ S.S.Yellow and N.Sativa oil showed insignificant change after the recovery period (table4).

The obtained results indicated that, AST and ALT activities (of serum and tissues) were still within the normal levels for all groups after the treatment and the recovery periods in comparison with the control group (Tables 5,6 and 7).

Administration of both $\mathrm{NaNO}_{3}$ and S.S.Yellow increased $(\mathrm{P}<0.01)$ serum activities of $\gamma-\mathrm{GT}, \mathrm{CPK}$ and alkaline phosphatase compared to those of the control till the end of the experiment. No significant changes of these enzymes activities were noted in group administered with N.S. Further, serum LDH activity exhibited a highly significant increase $(\mathrm{P}<0.01)$ in food additives treated group, after treated period only, as compared with the control ones. However, no significant changes were recorded in serum acid phosphatase activity in all groups. It was clear that administration of N.Sativa showed insignificant changes of all the tested enzymes activities throughout the experiment as shown in table (8) .

Table (9) shows that the total serum protein contents were significantly decreased $(\mathrm{P}<0.01)$ due to the mixture administration after the treatment period only. N.Sativa treatment caused insignificant changes in total serum protein content as compared to control rats. Total protein of brain, liver, muscle, kidney and heart revealed insignificant changes in all treated groups throughout the experimental period (Table 10). Concerning the effect of the mixture on serum albumin, the result showed a significant decrease $(\mathrm{P}<0.01)$ after the treatment period. While insignificant changes were recorded in both N.S treatment group and mixture treated groups after the recovery period. Whereas, the level of serum globulin recorded insignificant changes after the treatment period followed by a signif icant decrease after the recovery period in case of a mixture treated group. On the other hand, N.S treated group revealed a significant decrease in serum globulin $(\mathrm{P}<0.05)$ which was more pronounced $(\mathrm{P}<0.01)$ after the recovery period. A/G ratio recorded insignificant changes in all groups except that treated 
with N.S where it recorded a significant increase $(\mathrm{P}<0.01)$ after the recovery period only.

The data of serum and tissue total lipids, total cholesterol and, serum triglycerides are shown in tables (11 and 12). No significant differences between groups was found in serum and tissue total lipids, and serum triglycerides throughout the experimental period.
On the other hand, serum cholesterol showed a significant increase $(\mathrm{P}<0.01)$ in a mixture treated rats after a month of treatment. A highly significant elevation $(\mathrm{P}<0.01)$ was detected in cholesterol of brain, liver and heart for a mixture treated rats, but they were not affected by the administration of N.S. This elevation was not continued after the recovery period (Table, 13).

Table (1): Changes in body weight gain and in the ratio of organ weight/body weight of control, and treated rats after experimental and recovery periods .

\begin{tabular}{|c|c|c|c|c|c|c|c|}
\hline \multicolumn{2}{|c|}{ Periods and } & \multicolumn{3}{|c|}{ Treatmend period (30 days) } & \multicolumn{3}{|c|}{ Recovery period (15 days) } \\
\hline \multicolumn{2}{|l|}{ parameters } & Control & $\begin{array}{l}\mathrm{NaNO}_{3}+ \\
\text { Sunset- yellow }\end{array}$ & $\begin{array}{l}\mathrm{NaNO}_{3}+ \\
\text { s.s.y } \\
+\mathrm{N} . \mathrm{S} \text { oil } \\
\end{array}$ & Control & $\begin{array}{ll}\mathrm{NaNO}_{3} \quad+ \\
\text { Sunset- } \\
\text { yellow }\end{array}$ & $\begin{array}{l}\mathrm{NaNO}_{3}+\text { s.s.y } \\
+\mathrm{N} . \mathrm{S} \text { oil }\end{array}$ \\
\hline \multirow{3}{*}{$\begin{array}{l}\% \text { of body } \\
\text { weight change }\end{array}$} & $\overline{\mathrm{X}}$ & 19.6 & $11.9 * *$ & $17.0 * *$ & 18.94 & $10.6^{* *}$ & $15.0 * *$ \\
\hline & S.E & 0.26 & 0.69 & 0.8 & 0.4 & 0.4 & 0.8 \\
\hline & Signif. & & $\mathrm{P}<0.01$ & $\mathrm{P}<0.01$ & N.S. & $\mathrm{P}<0.01$ & $\mathrm{P}<0.01$ \\
\hline \multirow{3}{*}{ Kidney/b.wt } & $\mathrm{X}$ & 0.7 & 0.5 & 0.60 & 0.6 & 0.5 & 0.8 \\
\hline & S.E & 0.02 & 0.02 & 0.02 & 0.03 & 0.02 & 0.03 \\
\hline & Signif. & - & N.S. & N.S. & N.S. & N.S. & N.S. \\
\hline \multirow{3}{*}{ Brain/b.wt } & $\mathrm{X}$ & 0.86 & 0.86 & 0.86 & 0.9 & 0.85 & 0.89 \\
\hline & S.E & 0.03 & 0.03 & 0.04 & 0.02 & 0.04 & 0.03 \\
\hline & Signif. & - & N.S. & N.S. & N.S. & N.S. & N.S. \\
\hline \multirow{3}{*}{$\begin{array}{l}\text { Cardio- } \\
\text { somatic index }\end{array}$} & $\mathrm{X}$ & 0.6 & 0.4 & 0.6 & 0.62 & 0.45 & 0.5 \\
\hline & S.E & 0.02 & 0.02 & 0.02 & 0.04 & 0.02 & 0.03 \\
\hline & Signif. & - & N.S. & N.S. & N.S. & N.S. & N.S. \\
\hline \multirow{3}{*}{$\begin{array}{l}\text { Hepato- } \\
\text { somatic index }\end{array}$} & $X$ & 3.2 & 2.5 & 2.9 & 3.0 & 2.9 & 3.11 \\
\hline & S.E & 0.09 & 0.1 & 0.1 & 0.1 & 0.1 & 0.1 \\
\hline & Signif. & - & N.S. & N.S. & N.S. & N.S. & N.S. \\
\hline \multirow{3}{*}{$\begin{array}{l}\text { Gonado } \\
\text { somatic index }\end{array}$} & $\mathrm{X}$ & 1.07 & 0.9 & 0.81 & 1.1 & 0.8 & 0.84 \\
\hline & S.E & 0.02 & 0.05 & 0.04 & 0.02 & 0.05 & 0.04 \\
\hline & Signif. & - & N.S. & N.S. & N.S. & N.S. & N.S. \\
\hline
\end{tabular}

$$
\begin{aligned}
& \text { Signif. = Significant } \\
& *=<0.05 \\
& * *=<0.10
\end{aligned}
$$


Table (2): Effect of both sodium nitrite and sun-set yellow (10 mg $\mathrm{NaNO}_{3}$ and $0.5 \mathrm{mg}$ S.S.Yellow $/ \mathrm{kg}$ ) and N.Sativa. oil $(100 \mathrm{mg} / \mathrm{kg})$ on rectal temperature, respiratory rate and heart beats of albino rats after the experimental and recovery periods.

\begin{tabular}{|c|c|c|c|c|c|c|c|}
\hline \multicolumn{2}{|c|}{ Periods of treatment } & \multicolumn{3}{|c|}{ Treatment period (30 days) } & \multicolumn{3}{|c|}{ Recovery period (15 days) } \\
\hline \multicolumn{2}{|l|}{ Parameters } & Control & $\begin{array}{l}\mathrm{NaNO}_{3} \\
+ \\
\text { Sunset- } \\
\text { yellow }\end{array}$ & $\begin{array}{c}\mathrm{NaNO}_{3} \\
+ \text { S.S.Y } \\
+ \\
\text { N.Sativ } \\
\text { a oil }\end{array}$ & Control & $\begin{array}{c}\mathrm{NaNO}_{3}+ \\
\text { Sunset- } \\
\text { yellow }\end{array}$ & $\begin{array}{c}\mathrm{NaNO}_{3} \\
+ \text { S.S.Y } \\
+ \\
\text { N.Sativ } \\
\text { a oil }\end{array}$ \\
\hline \multirow{3}{*}{$\begin{array}{l}\text { Respiration } \\
\text { rate, } \\
\text { (breath/min) }\end{array}$} & $\bar{X}$ & 49.0 & $56.0^{* *}$ & 46.8 & 48.2 & 48.6 & 44.8 \\
\hline & S.E & 1.8 & 0.5 & 1.5 & 1.2 & 0.9 & 1.4 \\
\hline & Signif. & - & $<0.01$ & N.S. & N.S. & N.S. & N.S. \\
\hline \multirow{3}{*}{$\begin{array}{c}\text { Heartbeat rate, } \\
\text { Beat } / \mathrm{min}\end{array}$} & $\bar{X}$ & 136 & 139.6 & 143 & 134 & 133.6 & 134.6 \\
\hline & S.E & 1.8 & 0.7 & 2.5 & 1.8 & 1.1 & 1.2 \\
\hline & Signif. & - & N.S. & N.S. & N.S. & N.S. & N.S. \\
\hline \multirow{3}{*}{$\begin{array}{c}\text { Rectal } \\
\text { temperature, } \\
{ }^{\circ} \mathrm{C}\end{array}$} & $\bar{X}$ & 34.72 & 34.52 & 34.84 & 34.64 & 33.94 & $33.9 *$ \\
\hline & S.E & 0.09 & 0.7 & 0.3 & 0.15 & 0.4 & 0.3 \\
\hline & Signif. & - & N.S. & N.S. & N.S. & N.S. & $<0.05$ \\
\hline
\end{tabular}

Table (3): Effect of sodium nitrite $(10 \mathrm{mg} / \mathrm{kg})$ and sunset yellow $(0.5 \mathrm{mg} / \mathrm{kg})$ and N.S $(100 \mathrm{mg} / \mathrm{kg}$ ) on red blood cells (R.B.Cs), white blood cells (W.B.Cs), haemoglobin concentration $(\mathrm{HB} \%)$ and haematocrit value $(\mathrm{Hct} \%)$ of albino rats after experimental and recovery periods.

\begin{tabular}{|c|c|c|c|c|c|c|c|}
\hline \multirow{2}{*}{\multicolumn{2}{|c|}{$\begin{array}{c}\text { Periods and } \\
\text { treatment }\end{array}$}} & \multicolumn{3}{|c|}{ Treatment period (30 days) } & \multicolumn{3}{|c|}{ Recovery period (15 days) } \\
\hline & & \multirow{2}{*}{$\begin{array}{l}\text { Control } \\
8.5 \\
\end{array}$} & \multirow{2}{*}{$\begin{array}{l}\mathrm{NaNO}_{3}+ \\
\text { S.S.Yello } \\
\text { W } \\
6.9 * *\end{array}$} & \multirow{2}{*}{$\begin{array}{l}\mathrm{NaNO}_{3} \\
+ \text { S.S.Y } \\
+ \\
\text { N.Sativ } \\
\text { a oil } \\
7.6^{* *} \\
\end{array}$} & \multirow{2}{*}{$\begin{array}{l}\text { Control } \\
8.8^{*}\end{array}$} & \multirow{2}{*}{$\begin{array}{l}\mathrm{NaNO}_{3}+ \\
\text { S.S.Yello } \\
\text { w } \\
7.2 * *\end{array}$} & \multirow{2}{*}{$\begin{array}{l}\mathrm{NaNO}_{3} \\
+\mathrm{S} . \mathrm{S} . \mathrm{Y} \\
+ \\
\text { N.Sativ } \\
\text { a oil } \\
8.0 * * \\
\end{array}$} \\
\hline \multirow{3}{*}{$\begin{array}{l}\text { WBCs x } 10^{3} \\
\text { Cells/mm3 }\end{array}$} & $\bar{x}$ & & & & & & \\
\hline & S.E & 0.2 & 0.1 & 0.1 & 0.05 & 0.1 & 0.2 \\
\hline & Signif & - & $\mathrm{P}<0.01$ & $\mathrm{P}<0.01$ & N.S. & $\mathrm{P}<0.01$ & $\mathrm{P}<0.01$ \\
\hline \multirow{3}{*}{$\begin{array}{l}\text { RBCs x } 10^{6} \\
\text { Cells/mm3 }\end{array}$} & $\mathrm{X}$ & 5.88 & $4.9 *$ & $5.6^{* *}$ & 5.9 & 5.58 & $5.6^{*}$ \\
\hline & S.E & 0.05 & 0.05 & 0.05 & 0.07 & 0.16 & 0.12 \\
\hline & Signif & - & $\mathrm{P}<0.01$ & $\mathrm{P}<0.01$ & N.S. & N.S. & $\mathrm{P}<0.05$ \\
\hline \multirow{3}{*}{$\mathrm{Hb}, \mathrm{g} \%$} & $\bar{X}$ & 16 & $13.8^{* *}$ & $15.3 * *$ & 15.8 & $14.2 * *$ & $15.2 * *$ \\
\hline & S.E & 0.1 & 0.1 & 0.2 & 0.1 & 0.2 & 0.1 \\
\hline & $\begin{array}{l}\text { Signif } \\
\text {. }\end{array}$ & - & $\mathrm{P}<0.01$ & $\mathrm{P}<0.01$ & N.S. & $\mathrm{P}<0.01$ & $\mathrm{P}<0.01$ \\
\hline \multirow{3}{*}{ Hct $\%$} & $\overline{\mathrm{X}}$ & 41.4 & $36.8 * *$ & 39.4 & 42 & $37.2 * *$ & 41 \\
\hline & S.E & 0.9 & 0.05 & 0.2 & 0.9 & 0.5 & 0.6 \\
\hline & Signif & & $\mathrm{P}<0.01$ & N.S. & N.S. & $\mathrm{P}<0.01$ & N.S. \\
\hline
\end{tabular}


Table (4): Effect of sodium nitrite $(10 \mathrm{mg} / \mathrm{kg})$ and sunset yellow $(0.5 \mathrm{mg} / \mathrm{kg})$ and N.Sativa $(100 \mathrm{mg} / \mathrm{kg})$ on some biochemical parameters of albino rats after experimental and recovery periods.

\begin{tabular}{|c|c|c|c|c|c|c|c|}
\hline \multirow{2}{*}{\multicolumn{2}{|c|}{$\begin{array}{l}\text { Periods and } \\
\text { Treatment }\end{array}$}} & \multicolumn{3}{|c|}{ Treatment period (30 days) } & \multicolumn{3}{|c|}{ Recovery period (15 days) } \\
\hline & & \multirow{2}{*}{$\begin{array}{l}\text { Control } \\
93.6\end{array}$} & \multirow{2}{*}{$\begin{array}{l}\mathrm{NaNO}_{3}+ \\
\text { S.S.Yello } \\
\text { w } \\
134.4^{* *}\end{array}$} & \multirow{2}{*}{$\begin{array}{l}\text { NaNO3 } \\
+ \text { S.S.Y } \\
+ \\
\text { N.Sativ } \\
\text { a } \\
89.8\end{array}$} & Control & \multirow{2}{*}{$\begin{array}{l}\mathrm{NaNO}_{3}+ \\
\text { S.S.Yello } \\
\text { w } \\
105.8^{* *}\end{array}$} & $\begin{array}{l}\text { NaNO3 } \\
+ \text { S.S.Y } \\
+ \\
\text { N.Sativ } \\
\text { a } \\
\end{array}$ \\
\hline \multirow{3}{*}{ Glucose, $\mathrm{mg} / \mathrm{dl}$} & $\overline{\mathrm{X}}$ & & & & 92.4 & & 86.8 \\
\hline & S.E & 2 & 1.9 & 4 & 1.7 & 1.7 & 1.9 \\
\hline & Signif & & $\mathrm{P}<0.01$ & N.S. & N.S. & $\mathrm{P}<0.01$ & N.S. \\
\hline \multirow{3}{*}{$\begin{array}{l}\mathrm{T}_{3} \\
\mathrm{ng} / \mathrm{L}\end{array}$} & $\overline{\mathrm{X}}$ & 166 & $149 * *$ & $160.2 *$ & 157.8 & $148.8^{* *}$ & 158.0 \\
\hline & S.E & 1.8 & 1.8 & 1.6 & 1.1 & 0.9 & 2 \\
\hline & Signif & & $\mathrm{P}<0.01$ & $\mathrm{P}<0.05$ & N.S. & $\mathrm{P}<0.01$ & N.S. \\
\hline \multirow{3}{*}{$\begin{array}{l}\mathrm{T}_{4} \\
\mathrm{pg} / \mathrm{L}\end{array}$} & $\overline{\mathrm{X}}$ & 7.4 & $5.5^{* *}$ & 7.16 & 6.8 & $5.4^{* *}$ & $6.4^{*}$ \\
\hline & S.E & 0.3 & 0.1 & 0.3 & 0.09 & 0.1 & 0.18 \\
\hline & Signif & & $\mathrm{P}<0.01$ & N.S. & N.S. & $\mathrm{P}<0.01$ & $P<0.05$ \\
\hline \multirow{3}{*}{$\begin{array}{l}\mathrm{Ca}, \\
\mathrm{mg} / \mathrm{dl}\end{array}$} & $\overline{\bar{X}}$ & 7.9 & $9.875^{* *}$ & 7.6 & 7.5 & $8.7 * *$ & 7.4 \\
\hline & S.E & 0.2 & 0.2 & 0.2 & 0.18 & 0.2 & 0.18 \\
\hline & Signif & & $\mathrm{P}<0.01$ & N.S. & N.S. & $\mathrm{P}<0.01$ & N.S. \\
\hline \multirow{3}{*}{$\begin{array}{l}\text { Inorganic } \\
\text { Phosphorus, } \\
\mathrm{mg} / \mathrm{dl}\end{array}$} & $\overline{\mathrm{X}}$ & 12.04 & $9.9 * *$ & 11.4 & 11.94 & $10.8^{* *}$ & 11.8 \\
\hline & S.E & 0.18 & 0.2 & 0.2 & 0.18 & 0.2 & 0.2 \\
\hline & $\begin{array}{l}\text { Signif } \\
\text {. }\end{array}$ & & $\mathrm{P}<0.01$ & N.S. & N.S. & $\mathrm{P}<0.01$ & N.S. \\
\hline
\end{tabular}

Table (5): Serum AST and ALTactivities, (u/L) on rats after experimental and recovery periods.

\begin{tabular}{|c|c|c|c|c|c|c|c|}
\hline \multirow{2}{*}{\multicolumn{2}{|c|}{ Periods and }} & \multicolumn{3}{|c|}{ Treatment period (30 days) } & \multicolumn{3}{|c|}{ Recovery period (15 days) } \\
\hline & & \multirow{2}{*}{$\begin{array}{l}\text { Control } \\
23.8\end{array}$} & \multirow{2}{*}{$\begin{array}{l}\mathrm{NaNO}_{3}+ \\
\text { S.S.Yello } \\
\text { w } \\
37 * *\end{array}$} & \multirow{2}{*}{$\begin{array}{l}\mathrm{NaNO}_{3} \\
+ \\
\text { S.S.Y + } \\
\text { N.Sativ } \\
\text { a oil } \\
24.6\end{array}$} & \multirow{2}{*}{$\begin{array}{l}\text { Control } \\
21.2\end{array}$} & \multirow{2}{*}{$\begin{array}{l}\mathrm{NaNO}_{3}+ \\
\text { S.S.Yello } \\
\text { w } \\
27.4^{*}\end{array}$} & \multirow{2}{*}{$\begin{array}{l}\mathrm{NaNO}_{3}+ \\
\begin{array}{l}\text { S.S.Y } \\
\text { N.Sativa } \\
\text { oil }\end{array} \\
19.8\end{array}$} \\
\hline \multirow{3}{*}{$\begin{array}{l}\text { AST, } \\
(\mathrm{u} / \mathrm{L})\end{array}$} & $\bar{X}$ & & & & & & \\
\hline & S.E & 0.7 & 1.2 & 0.9 & 1 & 1 & 0.6 \\
\hline & Signif. & & $P<0.01$ & N.S & & $\mathrm{P}<0.05$ & N.S \\
\hline \multirow{3}{*}{$\begin{array}{l}\text { ALT, } \\
(\mathrm{u} / \mathrm{L})\end{array}$} & $\bar{X}$ & 22.2 & 28 & 22 & 17.8 & 28.4 & 20 \\
\hline & S.E & 1 & 1 & 1.1 & 0.5 & 1.1 & 0.7 \\
\hline & Signif. & - & $\mathrm{P}<0.05$ & N.S. & N.S. & $\mathrm{P}<0.05$ & N.S. \\
\hline
\end{tabular}


Table (6): AST activity of tissues (brain, liver, muscle, kidney and heart (u/gm)) of rats after the experimental and recovery periods.

\begin{tabular}{|c|c|c|c|c|c|c|c|}
\hline \multicolumn{2}{|l|}{ Periods and } & \multicolumn{3}{|c|}{ Treatment period (30 days) } & \multicolumn{3}{|c|}{ Recovery period (15 days) } \\
\hline \multicolumn{2}{|l|}{ Organs } & Control & $\begin{array}{l}\mathrm{NaNO}_{3}+ \\
\text { S.S.Yello } \\
\text { w }\end{array}$ & $\begin{array}{l}\mathrm{NaNO}_{3}+ \\
\text { S.S.Y + } \\
\text { N.Sativa } \\
\text { oil }\end{array}$ & Control & $\begin{array}{l}\mathrm{NaNO}_{3}+ \\
\text { S.S.Yello } \\
\text { w }\end{array}$ & $\begin{array}{l}\mathrm{NaNO}_{3} \\
+ \\
\text { S.S.Y + } \\
\text { N.Sativa } \\
\text { oil } \\
\end{array}$ \\
\hline \multirow{3}{*}{ Brain } & $\bar{X}$ & 15.0 & $24.4 * *$ & $18.1^{*}$ & 14.2 & $21.6^{* *}$ & $19.4^{*}$ \\
\hline & S.E & 0.4 & 0.9 & 0.7 & 0.7 & 0.5 & 0.4 \\
\hline & Signif. & - & $\mathrm{P}<0.01$ & $\mathrm{P}<0.05$ & & $\mathrm{P}<0.01$ & $\mathrm{P}<0.05$ \\
\hline \multirow{3}{*}{ Liver } & $\mathrm{X}$ & 18 & $26.2 * *$ & 18.8 & 17.2 & 17.2 & 16 \\
\hline & S.E & 1.1 & 0.5 & 0.7 & 0.8 & 1.1 & 0.7 \\
\hline & Signif. & - & $\mathrm{P}<0.01$ & N.S & & N.S & N.S \\
\hline \multirow{3}{*}{ Muscle } & $X$ & 16.6 & $21.0 * *$ & 18 & 16.8 & 14.8 & 18 \\
\hline & S.E & 1.4 & 1.1 & 0.8 & 1.7 & 0.9 & 0.7 \\
\hline & Signif. & - & $\mathrm{P}<0.01$ & N.S & & N.S & N.S \\
\hline \multirow{3}{*}{ Kidney } & $\overline{\mathrm{X}}$ & 18.8 & 20.3 & 14.8 & 17.0 & 16.6 & 14.4 \\
\hline & S.E & 1.2 & 1.5 & 0.8 & 0.7 & 1.6 & 0.9 \\
\hline & Signif. & - & N.S & N.S & & N.S & N.S \\
\hline \multirow{3}{*}{ Heart } & $\mathrm{X}$ & 13.4 & $20.6^{*}$ & 18 & 13.8 & 11.4 & 15.6 \\
\hline & S.E & 0.5 & 1.4 & 0.7 & 0.9 & 0.7 & 1 \\
\hline & Signif. & - & $\mathrm{P}<0.05$ & N.S & & N.S & N.S \\
\hline
\end{tabular}

Table (7): ALT activity in brain, liver, muscle, kidney and heart tissues of rats during the treatment and recovery periods.

\begin{tabular}{|c|c|c|c|c|c|c|c|}
\hline \multirow{2}{*}{\multicolumn{2}{|c|}{ Organs }} & \multicolumn{3}{|c|}{ Treatment period (30 days) } & \multicolumn{3}{|c|}{ Recovery period (15 days) } \\
\hline & & \multirow{2}{*}{$\begin{array}{l}\text { Control } \\
14 \\
\end{array}$} & \multirow{2}{*}{$\begin{array}{l}\mathrm{NaNO}_{3}+ \\
\text { S.S.Yello } \\
\text { w } \\
23.2\end{array}$} & \multirow{2}{*}{$\begin{array}{l}\mathrm{NaNO}_{3}+ \\
\text { S.S.Y + } \\
\text { N.Sativa } \\
14\end{array}$} & \multirow{2}{*}{$\begin{array}{l}\text { Control } \\
14.2\end{array}$} & \multirow{2}{*}{$\begin{array}{l}\mathrm{NaNO}_{3}+ \\
\text { S.S.Yelloe }\end{array}$} & \multirow{2}{*}{$\begin{array}{l}\mathrm{NaNO}_{3} \\
+ \\
\text { S.S.Y + } \\
\text { N.Sativa } \\
15.4\end{array}$} \\
\hline Brain & $\overline{\mathrm{X}}$ & & & & & & \\
\hline Drani & S.E & 0.7 & 2 & 1.1 & 0.5 & 0.4 & 0.5 \\
\hline & Signif. & - & N.S. & N.S. & N.S. & N.S. & N.S. \\
\hline \multirow{3}{*}{ Liver } & $\bar{X}$ & 16.4 & 24.2 & 16 & 15.2 & 21.2 & 16 \\
\hline & S.E & 0.5 & 2 & 1.2 & 0.6 & 0.6 & 0.7 \\
\hline & Signif. & - & N.S. & N.S. & N.S. & N.S. & N.S. \\
\hline \multirow{3}{*}{ Muscle } & $\mathrm{X}$ & 18.6 & 24.2 & 18.4 & 16.4 & 21.4 & 14.6 \\
\hline & S.E & 0.2 & 1.1 & 1 & 1.2 & 0.4 & 1.1 \\
\hline & Signif. & - & N.S. & N.S. & N.S. & N.S. & N.S. \\
\hline \multirow{3}{*}{ Kidney } & $\bar{X}$ & 16 & 20.6 & 16.8 & 15.2 & 17.4 & 13.6 \\
\hline & S.E & 0.7 & 0.4 & 1 & 0.9 & 0.9 & 2.1 \\
\hline & Signif. & - & N.S. & N.S. & N.S. & N.S. & N.S. \\
\hline \multirow{3}{*}{ Heart } & $\overline{\mathrm{X}}$ & 18.8 & 21.4 & 15.2 & 16.4 & 18.6 & 15 \\
\hline & S.E & 0.6 & 0.8 & 1.1 & 0.02 & 0.5 & 0.9 \\
\hline & Signif. & - & N.S. & N.S. & N.S. & N.S. & N.S. \\
\hline
\end{tabular}


Table (8): Effect of sodium nitrite $(10 \mathrm{mg} / \mathrm{kg})$ and sunset yellow $(0.5 \mathrm{mg} / \mathrm{kg})$ and N.Sativa $(100 \mathrm{mg} / \mathrm{kg})$ on some biochemical parameters of albino rats after experimental and recovery periods.

\begin{tabular}{|c|c|c|c|c|c|c|c|}
\hline \multicolumn{2}{|l|}{ Periods and } & \multicolumn{3}{|c|}{ Treatment period (30 days) } & \multicolumn{3}{|c|}{ Recovery period (15 days) } \\
\hline \multicolumn{2}{|l|}{ Parameters } & Control & $\begin{array}{c}\mathrm{NaNO}_{3}+ \\
\text { S.S.Yellow }\end{array}$ & $\begin{array}{c}\mathrm{NaNO}_{3}+ \\
\text { S.S.Y + } \\
\text { N.Sativa oil }\end{array}$ & Control & $\begin{array}{c}\mathrm{NaNO}_{3}+ \\
\text { S.S.Yellow }\end{array}$ & $\begin{array}{c}\mathrm{NaNO}_{3}+ \\
\text { S.S.Y }+ \\
\text { N.Sativa oil }\end{array}$ \\
\hline \multirow{3}{*}{$\begin{array}{l}\text { GGT, } \\
\text { U/L }\end{array}$} & $\vec{X}$ & 16.8 & $37.2^{* *}$ & $24.8 * *$ & 16.8 & $31.0^{* *}$ & 15.2 \\
\hline & S.E & .7 & .9 & 3.2 & .5 & .4 & .4 \\
\hline & Signif. & & $P<0.01$ & $\mathrm{P}<0.01$ & & $\mathrm{P}<0.01$ & N.S \\
\hline \multirow{3}{*}{$\begin{array}{l}\mathrm{LDH}, \\
\mathrm{U} / \mathrm{L}\end{array}$} & $\mathrm{X}$ & 245.0 & $266.0^{*}$ & 255.0 & 244.1 & 246.0 & 235.1 \\
\hline & S.E & 2.2 & 2.4 & 5.0 & 2.6 & 2.4 & 4.4 \\
\hline & Signif. & & $P<0.05$ & N.S & & N.S & N.S \\
\hline \multirow{3}{*}{$\begin{array}{l}\text { CPK, } \\
\text { U/L }\end{array}$} & $\mathrm{X}$ & 55.0 & $74.0^{* *}$ & 62.0 & 54.0 & 63.0 & 54.4 \\
\hline & S.E & 2.2 & 2.4 & 3.7 & 1.8 & 2.0 & 2.3 \\
\hline & Signif. & & $\mathrm{P}<0.01$ & N.S & & N.S & N.S \\
\hline \multirow{3}{*}{$\begin{array}{l}\text { Alkaline } \\
\text { phosphatase, } \\
\text { Iu/L }\end{array}$} & $\bar{X}$ & 126.0 & $106.0 *$ & $90.0^{* *}$ & 91.0 & $115.0^{*}$ & 91.5 \\
\hline & S.E & 0.6 & 1.8 & 3.0 & .9 & 2.2 & 4.1 \\
\hline & Signif & & $\mathrm{P}<0.05$ & $\mathrm{P}<0.01$ & & $\mathrm{P}<0.05$ & N.S \\
\hline \multirow{3}{*}{$\begin{array}{l}\text { Acid phosphatase } \\
\text { U/L }\end{array}$} & $X$ & 9.0 & 10.6 & 9.6 & 10.4 & 11.2 & 10.6 \\
\hline & S.E & .6 & .4 & .5 & .2 & .3 & .2 \\
\hline & Signif. & & $N . S$ & N.S & & N.S & N.S \\
\hline
\end{tabular}

Table (9): Serum total protein, albumin glubulin and $A / G$ ratio of rats after the treatment and recovery periods.

\begin{tabular}{|c|c|c|c|c|c|c|c|}
\hline \multirow{2}{*}{\multicolumn{2}{|c|}{$\begin{array}{l}\text { Periods and } \\
\text { treatment }\end{array}$}} & \multicolumn{3}{|c|}{ Treatment period (30 days) } & \multicolumn{3}{|c|}{ Recovery period (15 days) } \\
\hline & & \multirow{2}{*}{$\begin{array}{r}\text { Control } \\
8.34\end{array}$} & \multirow{2}{*}{$\begin{array}{c}\begin{array}{c}\mathrm{NaNO}_{3}+ \\
\text { S.S.Yello } \\
\text { w }\end{array} \\
6.48^{* *}\end{array}$} & \multirow{2}{*}{$\begin{array}{c}\mathrm{NaNO}_{3}+ \\
\text { S.S.Y + } \\
\text { N.Sativa } \\
\text { oil } \\
7.56^{*} \\
\end{array}$} & \multirow{2}{*}{$\begin{array}{c}\text { Control } \\
7.9 \\
\end{array}$} & \multirow{2}{*}{$\begin{array}{c}\mathrm{NaNO}_{3}+ \\
\text { S.S.Yello } \\
\text { w }\end{array}$} & \multirow{2}{*}{$\begin{array}{c}\begin{array}{c}\mathrm{NaNO}_{3}+ \\
\text { S.S.Y }+ \\
\text { N.Sativa oil }\end{array} \\
6.6^{* *}\end{array}$} \\
\hline \multirow{3}{*}{$\begin{array}{l}\text { Protein } \\
\mathrm{g} / \mathrm{dl}\end{array}$} & $\overline{\mathrm{X}}$ & & & & & & \\
\hline & S.E & 0.3 & 0.03 & 0.2 & 0.16 & 0.19 & 0.19 \\
\hline & Signif. & - & $\mathrm{P}<0.01$ & $\mathrm{P}<0.05$ & N.S. & N.S. & $\mathrm{P}<0.05$ \\
\hline \multirow{3}{*}{$\begin{array}{l}\text { Albumin, } \\
\mathrm{g} / \mathrm{dl}\end{array}$} & $\mathrm{X}$ & 5.54 & 4.22 & 5.6 & 4.9 & 4.84 & $5.66^{* *}$ \\
\hline & S.E & 0.1 & 0.1 & 0.1 & 0.14 & 0.09 & 0.09 \\
\hline & Signif. & - & $\begin{array}{l}\mathrm{P}<0.01 \\
\end{array}$ & N.S. & N.S. & N.S. & $\mathrm{P}<0.01$ \\
\hline \multirow{3}{*}{$\begin{array}{l}\text { Glubulin } \\
\mathrm{g} / \mathrm{dl}\end{array}$} & $\bar{X}$ & 2.71 & 2.14 & 1.86 & 3.1 & 2.6 & 2.1 \\
\hline & S.E & 0.13 & 0.17 & 0.12 & 0.1 & 0.18 & 0.1 \\
\hline & Signif. & - & N.S. & N.S. & N.S. & N.S. & N.S. \\
\hline \multirow{3}{*}{$\mathrm{A} / \mathrm{G}$, ratio } & $\bar{X}$ & 2.04 & 1.98 & 2.66 & 1.58 & 1.76 & 2.64 \\
\hline & S.E & 0.1 & 0.18 & 0.2 & 0.1 & 0.22 & 0.44 \\
\hline & Signif. & - & N.S. & N.S. & N.S. & N.S. & N.S. \\
\hline
\end{tabular}


Table (10): Tissue total protein (brain, liver, muscle, kidney and heart) of rats after the treatment and recovery periods.

\begin{tabular}{|c|c|c|c|c|c|c|c|}
\hline \multirow{2}{*}{\multicolumn{2}{|c|}{ Periods and }} & \multicolumn{3}{|c|}{ Treatment period (30 days) } & \multicolumn{3}{|c|}{ Recovery period (15 days) } \\
\hline & & \multirow{2}{*}{$\begin{array}{l}\text { Control } \\
110.4\end{array}$} & \multirow{2}{*}{$\begin{array}{c}\begin{array}{c}\mathrm{NaNO}_{3} \\
+ \\
\text { S.S.Yellow }\end{array} \\
110\end{array}$} & \multirow{2}{*}{$\begin{array}{c}\mathrm{NaNO}_{3} \\
+ \\
\text { S.S.Yellow }+ \\
\text { N.Sativa oil } \\
118\end{array}$} & \multirow{2}{*}{$\begin{array}{c}\text { Control } \\
110\end{array}$} & \multirow{2}{*}{$\begin{array}{c}\begin{array}{c}\mathrm{NaNO}_{3} \\
+ \\
\text { S.S.Yellow }\end{array} \\
110.5\end{array}$} & \multirow{2}{*}{$\begin{array}{c}\begin{array}{c}\mathrm{NaNO}_{3} \\
+ \\
\text { S.S.Yellow } \\
+ \\
\text { N.Sativa }\end{array} \\
116.6\end{array}$} \\
\hline Rrain & $\bar{X}$ & & & & & & \\
\hline Diant & S.E & 0.6 & 0.7 & 0.7 & 0.7 & 0.8 & 0.4 \\
\hline & Signif. & - & N.S. & N.S. & N.S. & N.S. & N.S. \\
\hline \multirow{3}{*}{ Liver } & $\overline{\mathrm{X}}$ & 56 & 55 & 55 & 50 & 53.6 & 57 \\
\hline & S.E & 1.8 & 2.2 & 2.7 & 3.5 & 2.4 & 2.3 \\
\hline & Signif. & - & N.S. & 91.0 & N.S. & N.S. & N.S. \\
\hline \multirow{3}{*}{ Muscle } & $\mathrm{X}$ & 92 & 90.8 & 21 & 92.4 & 91.4 & 92.4 \\
\hline & S.E & 1.2 & 0.9 & 0.4 & 0.4 & 0.9 & 1.7 \\
\hline & Signif. & - & N.S. & N.S. & N.S. & N.S. & N.S. \\
\hline \multirow{3}{*}{ Kidney } & $\bar{X}$ & 68.4 & 64.6 & 69.4 & 67.6 & 64.2 & 67.2 \\
\hline & S.E & 0.9 & 2.1 & 0.6 & 1 & 1.5 & 1.2 \\
\hline & Signif. & - & N.S. & N.S. & N.S. & N.S. & N.S. \\
\hline \multirow{3}{*}{ Heart } & $X$ & 88 & 85.2 & 88.8 & 87 & 88.6 & 82 \\
\hline & S.E & 0.9 & 1.5 & 0.4 & 1.1 & 0.4 & 1.1 \\
\hline & Signif. & - & N.S. & N.S. & N.S. & N.S. & N.S. \\
\hline
\end{tabular}

Table (11): Serum total lipids, cholesterol and triglycerids in rats after treatment and recovery periods of rats .

\begin{tabular}{|c|c|c|c|c|c|c|c|}
\hline \multirow{2}{*}{\multicolumn{2}{|c|}{ Periods of }} & \multicolumn{3}{|c|}{ Treatmentd period (30 days) } & \multicolumn{3}{|c|}{ Recovery period (15 days) } \\
\hline & & \multirow{2}{*}{$\begin{array}{l}\text { Control } \\
388.4\end{array}$} & \multirow{2}{*}{$\begin{array}{l}\mathrm{NaNO}_{3}+ \\
\text { S.S.Yellow } \\
390.1\end{array}$} & \multirow{2}{*}{$\begin{array}{l}\mathrm{NaNO}_{3}+ \\
\text { S.S.Y + } \\
\text { N.Sativa } \\
376.2\end{array}$} & \multirow{2}{*}{$\begin{array}{l}\text { Control } \\
382.0\end{array}$} & \multirow{2}{*}{$\begin{array}{l}\mathrm{NaNO}_{3}+ \\
\text { S.S.Yello } \\
\text { w } \\
388.5\end{array}$} & \multirow{2}{*}{$\begin{array}{l}\mathrm{NaNO}_{3}+ \\
\text { S.S.Y + } \\
\text { N.Sativa } \\
358.3\end{array}$} \\
\hline \multirow{3}{*}{$\begin{array}{l}\text { Total lipids, } \\
\mathrm{mg} / \mathrm{dl}\end{array}$} & $\bar{X}$ & & & & & & \\
\hline & S.E & 4.8 & 5.1 & 9 & 7.3 & 7.3 & 5 \\
\hline & Signif. & - & N.S. & N.S. & N.S. & N.S. & N.S. \\
\hline \multirow{3}{*}{$\begin{array}{l}\text { Cholesterol, } \\
\mathrm{mg} / \mathrm{dl}\end{array}$} & $\mathrm{X}$ & 131.0 & $150.0 *$ & 129.0 & 129.0 & 136.0 & $105.2 *$ \\
\hline & S.E & 4.5 & 4 & 1.6 & 7.8 & 4 & 1.5 \\
\hline & Signif. & - & $P<0.05$ & N.S. & N.S. & N.S. & $\mathrm{P}<0.05$ \\
\hline \multirow{3}{*}{$\begin{array}{l}\text { Triglycerides, } \\
\text { mg/dl }\end{array}$} & $X$ & 98.1 & $118.0^{*}$ & 98.0 & 90.8 .1 & 99.2 & 93.4 \\
\hline & S.E & 3.7 & 5.8 & 5.8 & 1.7 & 3.5 & 3.7 \\
\hline & Signif. & - & $\mathrm{P}<0.05$ & N.S. & N.S. & N.S. & N.S. \\
\hline
\end{tabular}


Table (12): Tissue (brain, liver, muscle, kidney and heart) total lipids of rats after the treatment and recovery periods.

\begin{tabular}{|c|c|c|c|c|c|c|c|}
\hline \multirow{2}{*}{\multicolumn{2}{|c|}{ Periods of }} & \multicolumn{3}{|c|}{ Treatment period (30 days) } & \multicolumn{3}{|c|}{ Recovery period (15 days) } \\
\hline & & \multirow{2}{*}{$\begin{array}{c}\text { Control } \\
49\end{array}$} & \multirow{2}{*}{$\begin{array}{c}\underset{\mathrm{NaNO}_{3}+}{\text { S.S.Yellow }} \\
\qquad 58\end{array}$} & \multirow{2}{*}{$\begin{array}{c}\mathrm{NaNO}_{3+} \\
+\mathrm{S} . \mathrm{S} . Y e l \\
\text { low }+ \\
\begin{array}{c}\text { N.Sativa } \\
\text { oil }\end{array} \\
55\end{array}$} & \multirow{2}{*}{$\begin{array}{c}\text { Control } \\
51.6\end{array}$} & \multirow{2}{*}{$\begin{array}{c}\underset{\mathrm{NaNO}_{3+}}{\text { S.S.Yellow }} \\
\qquad 52\end{array}$} & \multirow{2}{*}{$\begin{array}{c}\mathrm{NaNO}_{3}+ \\
\begin{array}{c}\text { S.S.Y }+ \\
\text { N.Sativa } \\
\text { oil }\end{array} \\
50.4\end{array}$} \\
\hline \multirow{3}{*}{ Brain } & $\bar{X}$ & & & & & & \\
\hline & S.E & 1.8 & 4.1 & 2.7 & 2.6 & 2.5 & 2.7 \\
\hline & Signif. & - & N.S. & N.S. & N.S. & N.S. & N.S. \\
\hline \multirow{3}{*}{ Liver } & $\bar{X}$ & 92.6 & 99 & 93.6 & 92 & 96 & 93.2 \\
\hline & S.E & 2.8 & 2.4 & 1.6 & 2.5 & 1.4 & 1.2 \\
\hline & Signif. & - & N.S. & N.S. & N.S. & N.S. & N.S. \\
\hline \multirow{3}{*}{ Muscle } & $\mathrm{X}$ & 46.4 & 56.2 & 47 & 45 & 47 & 44 \\
\hline & S.E & 2.7 & 4.1 & 2 & 2.8 & 1.2 & 2.4 \\
\hline & Signif. & - & N.S. & N.S. & N.S. & N.S. & N.S. \\
\hline \multirow{3}{*}{ Kidney } & $\mathrm{X}$ & 44.4 & 53.2 & 45 & 45 & 48.2 & 42.5 \\
\hline & S.E & 1.5 & 3.8 & 3.1 & 1.4 & 1.3 & 2.2 \\
\hline & Signif. & - & N.S. & N.S. & N.S. & N.S. & N.S. \\
\hline \multirow{3}{*}{ Heart } & $\bar{X}$ & 53.6 & 55.8 & 56 & 49.6 & 44.8 & 41 \\
\hline & S.E & 1.8 & 2.3 & 2.4 & 2.2 & 5.2 & 1 \\
\hline & Signif. & - & N.S. & N.S. & N.S. & N.S. & N.S. \\
\hline
\end{tabular}

Table (13): Tissue total cholesterol ( brain, liver, muscle, kidney and heart) of rats after the teatment and recovery periods.

\begin{tabular}{|c|c|c|c|c|c|c|c|}
\hline \multirow{2}{*}{\multicolumn{2}{|c|}{ Periods of Treatment }} & \multicolumn{3}{|c|}{ Treatment period (30 days) } & \multicolumn{3}{|c|}{ Recovery period (15 days) } \\
\hline & & \multirow{2}{*}{$\begin{array}{l}\text { Control } \\
34.4\end{array}$} & \multirow{2}{*}{$\begin{array}{l}\mathrm{NaNO}_{3}+ \\
\text { S.S.Yello } \\
\text { w }\end{array}$} & \multirow{2}{*}{$\begin{array}{l}\mathrm{NaNO}_{3}+ \\
\text { S.S.Y + } \\
\text { N.Sativa } \\
\text { oil } \\
30.8\end{array}$} & \multirow{2}{*}{$\begin{array}{l}\text { Control } \\
33.8\end{array}$} & \multirow{2}{*}{$\begin{array}{l}\mathrm{NaNO}_{3}+ \\
\text { S.S.Yello } \\
\text { w }\end{array}$} & \multirow{2}{*}{$\begin{array}{l}\mathrm{NaNO}_{3} \\
+ \\
\text { S.S.Y + } \\
\text { N.Sativa } \\
19.1^{* *}\end{array}$} \\
\hline \multirow{3}{*}{ Brain } & $\bar{X}$ & & & & & & \\
\hline & S.E & 1.6 & 2.1 & 0.5 & 1.2 & 2.2 & 0.6 \\
\hline & Signif. & - & $P<0.01$ & N.S. & N.S. & N.S. & $\mathrm{P}<0.01$ \\
\hline \multirow{3}{*}{ Liver } & $\mathrm{X}$ & 28 & $39.2 * *$ & 16 & 30.8 & 26.4 & $15.2 * *$ \\
\hline & S.E & 0.9 & 1.6 & 0.7 & 1.8 & 1.5 & 1.1 \\
\hline & Signif. & - & $P<0.01$ & N.S. & N.S. & N.S. & $\mathrm{P}<0.01$ \\
\hline \multirow{3}{*}{ Muscle } & $\mathrm{X}$ & 17.2 & 21.8 & 14 & 14.2 & 15.2 & $14.6^{* *}$ \\
\hline & S.E & 0.9 & 2.5 & 0.7 & 0.9 & 1.1 & 0.9 \\
\hline & Signif. & - & N.S. & N.S. & N.S. & N.S. & $\mathrm{P}<0.01$ \\
\hline \multirow{3}{*}{ Kidney } & $\bar{X}$ & 14.4 & 16.4 & $31.2 * *$ & 13 & 17.6 & 31.2 \\
\hline & S.E & 0.7 & 0.7 & 1.1 & 0.9 & 2.1 & 1.1 \\
\hline & Signif. & - & N.S. & $\mathrm{P}<0.01$ & N.S. & N.S. & N.S. \\
\hline \multirow{3}{*}{ Heart } & $\overline{\mathrm{X}}$ & 18.4 & $23.8^{* *}$ & 17.6 & 17 & 21 & 15 \\
\hline & $\begin{array}{l}\text { S.E } \\
\end{array}$ & 0.8 & 1.2 & 1 & 0.9 & 1.8 & 0.7 \\
\hline & Signif. & - & $P<0.01$ & N.S. & N.S. & N.S. & N.S. \\
\hline
\end{tabular}




\section{Discussion}

The present observations of body weight loss after the treatment with both food preservator and food colorant may be due to the reduction of food utilization. (Grant and Butler, 1989). On the other hand, the reduction of mean body weight may be due to the increase in the level of both nitrite and sunset yellow leading to increased catabolic processes in the body. Green blatt and Mirvish (1972), Maekawa et al. (1982) and Til et al. (1988) recorded reductions of body weight gain due to nitrite treatments. Many investigators recorded a reduction in body weight as a result of colorants supplementation (Brozelleca et al., 1989; Osman et al., 1995 and Abu El-Zahab et al., 1997) In the presenent findings, it was clear that N.S. oil amliorate the catabolic effect of both $\mathrm{NaO}_{3}$ and S.S. Yellow.

The present result did not show statistically significant changes of the relative weight of the tested organs of $\mathrm{Hb} \%$ and $\mathrm{Hct} \%$. It is known that nitrites convert the ferrous ion of haemoglobin to ferric ion both in vivo and vitro (Ganong, 1997). This can explain the reduction of haemoglobin level. In the other words, administration of both nitrite and S.S.Yellow leads to haemotopoietic tissue hypoxia resulting on the long term (one month in the present study) to a decrease of red blood cell production and hence to reduction of blood haemoglobin level.

The decrease of haemoglobin due to nitrite treatment has been reported using different animals including rats (Abdel-Rahim et al., 1988, Smith, 1991 and Reutov et al., 1993), mice (Walker et al., 1957), dogs (Harely and Robin, 1962), Swine and Sheep (London et al., 1967). Further, nitrites have been reported to induce a reduction of the male rats treated with $\mathrm{NaNO}_{3}+$ S.S.Yellow or with $\mathrm{NaNO}_{3}+$ S.S.Yellow + N.Sativa. Hirose et al. (1993); Fujitani (1993) and Yoshidae et al. (1994) reported an increase of absolute and relative liver and kidney weights of rats treated with sodium nitrite. These results are not in harmony with those of the present work. This could be due to the lesions and other disturbances (Dini et al., 1992, and Hirose et al., 1993) leading to loss of nutrient and fluids or to inhibition of gastrointestinal mucosa $\mathrm{Na}^{+} / \mathrm{K}^{+}$, ATP ase and alkaline phosphatase (BruningFann and Kaneene, 1993).

The present results revealed that body temperature, respiration rate and heart beats are almost the same in all groups even under the treatment conditions.

Administration of both sod. Nitrite and S.S.Yellow for one month to rats induced a decrease of W.B.Cs, R.B.Cs, haemoglobin level in human (Heisler et al., 1974 and White, 1975).

The present results are, in part, comparable to those obtained by Rastogi and Prasad (1983a\&b) where they found that feeding of albino mice in the common food colour material yellow led to changes in hematological values. Total erythrocyte count and hemoglobin had decreased. Erythrocyte sedimentation rate (ESR), mean corpuscular volume (MCV) and mean corpuscular hemoglobin concentration (MCHC) had increased. These observations suggested the occurrence of normochromic macrocytic anemia.

Differential leukocyte count showed marked increase in the number of lymphocytes and monocytes and decrease in the number of neutrophils and eosinophils (Rastogi and Prasad, 
1983 b). The present study was in accordance with Mackenzic et al. (1992) who found a reduction in total white blood cell counts as a result of caramel treatment in rats. Also, it was clear that treatment in the present study had ameliorate all the haematological variation.

Treating the rats with both $\mathrm{NaNO}_{3}$ and S.S.Yellow induced a gradual significant increase of the blood sugar level. However, one can expect that sodium nitrite produced hyperglycemia to be due to deficiency of insulin release. It is known that nitric oxide is formed from nitrites (and nitrate) at least by the vascular epithelial cells (Harrison and Bates, 1993 and Katzung, 1995). Both nitric oxide and nitrites open potassium channel (Katzung, 1995) which through closing voltage gated. Calcium channels decreases intracellular calcium. Calcium is known to trigger insulin secretion, \{(calcium channel blockers are known to produce hyperglycemia (Katzung, 1995)\}.

The present results go in parallel with those reported on the hyperglycemic effect of sodium nitrite in rats (Abdel-Rahim et al., 1988 and Shelpov et al., 1991). They reported that in presence of nitrite ion, the activity of amylase increase beside an inhibition of adrenaline-induced activation of phosphorylase. This results in the liberation of glucose from glycogen, so blood glucose increases while liver glycogen decreases.

The elevation of level of serum glucose was also interpreted by the effect of sun-set yellow on enzyme system of the glycolytic pathway. It is not surprising to find an enhanced hyperglycemia due to combination of sodium nitrite and sun set-yellow treatment of the rates. Each of the two compounds acts through separate pathways and hence there is no antagonism for their effects. The observed improvement shown in glucose in treated group may be due to the action of N.S oil as antioxidant. These results are in contrast with Rasekh et al. (1991) who observed hyperglycemic effect of N.Sativa in rats.

The present study revealed that administration of sod.nitrite and sunset yellow to rats caused variable degree of stimulation of thyroid gland function after treated and recovery periods. This was proved by the significant increase in serum thyroid hormones $T_{3}$ and $T_{4}$. The interaction between sod.nitrite and sun set yellow may give a new chemical component, which has a stimulatory effect on thyroid gland. This effect could be attributed to its chemical structure that can compete with thyroxine-binding globulin leading to its deficiency and to hyperthyroidism by feed-back mechanism (Gold and Vladutin, 1994).

These changes in thyroid hormones could also be resulted from alteration in the pituitary-thyroid axis as a consequence of the stressing effect of this new component. This was in accordance with El-Saadaney (1991).It is known that thyroid hormones enter the brain, large doses of thyroid hormones cause irritability, restlessness and rapid mentation. Thyroid hormones also have marked effect on brain development. (Ganong, 1997, Guyton and Hall, 1998).

The present work concluded that, the studied food additives can markedly alter the endocrine function of thyroid gland leading to hyper function, that might play a role in children hyper activity probably through affecting of higher centers in the brain. It is also clear that N.S ameliorate. This damage effect due to its antioxidant property. This could be by blocking the 
generation and propagation of free radicals.

The results of this study demonstrated that the administration of (NaNO3 + S.S.Yellow) caused a significant increase in serum calcium level. This observation was similarly recorded by Sharma (1989) who recorded higher values of minerals in rats treated with metanil- yellow. On the other hand, the present results showed a significant decrease in serum phosphate after treatment with the mixture of $\mathrm{NaNO}_{3}$ and S.S.Yellow. It is also clear that N.Sativa could not ameliorate the effect of this new compound $\left(\mathrm{NaNO}_{3}+\right.$ S.S.Yellow) on serum phosphate during the treated period, while after the recovery period it turn back to the normal value in N.Sativa treated group. Helal et al. (2000) stated that S.S.Yellow did not affect serum level of both Calcium and Phosphorus. So, the present results may be due to the new compound (resulted from the reaction between both $\mathrm{NaNO}_{3}$ and S.S.Yellow).

In the present work, both $\gamma \mathrm{GT}$ and alkaline Phosphatase (AP) were increased in the group of rats given $\left(\mathrm{NaNO}_{3}+\right.$ S.S.Yellow). However, the significant reduction in $\gamma \mathrm{GT}$ and AP activities in N.Sativa treated group may be due to the good effect of the N.Sativa to improve the activity of liver cells or to stop the damage of liver cell membranes and hence the release of their enzymes. The insignificant changes in AST and ALT activities in all treated groups may be due to less sensitivity of AST and ALT activities than $\gamma \mathrm{GT}$.

Many enzymes like alkaline phosphate (AP) and $\gamma \mathrm{GT}$ tend to be released into plasma in large amounts following the hepatocellular damage (Whitby et al., 1992). Gamma glutamyle transferase is considered to be more specific for liver function tests, its activity is markedly increased in plasma in both primary and secondary carcinoma of liver (Whitby et al., 1992).

The effect of $\mathrm{NaNO}_{3}$ and S.S.Yellow mixture on serum enzyme activities (LDH and CPK) in this study provides further evidence on the effect of this mixture on the liver and heart. This elevation could be attributed to a generalized increase in membrane activity and is particularly useful in the diagnosis of muscular disorder, especi ally progressive muscular dystrophy (Doran and Wilkinson, 1975; Ebashi et al., 1959).

The present study showed a significant increase in serum LDH activity indicating cellular damage. Morliere et al. (1991) reported that increased lipid peroxidation is accompanied by the release of $\mathrm{LDH}$ reflecting membrane damage. Furthermore, Rybczynska et al. (1996) found that lipid peroxidation of cell membranes is associated with inactivation of membrane bound enzymes. Based on these molecular events, it is possible to explain systemic and metabolic responses evidenced in the present study by elevated activity of serum LDH as well as increased contents of cholesterol, in addition to a drop in total protein content of a mixture $\left(\mathrm{NaNO}_{3}+\mathrm{S}\right.$.S.Yellow $)$ treated rats, which are reduced to reach normal levels after treatment with N.Sativa.

The results of the present study demonstrated that N.Sativa oil offer some protection against the mixture of $\mathrm{NaNO}_{3} \&$ S.S.Yellow induced toxicity in rat and reduced many undesired changes of liver tissue and may be used as powerful antioxidant against this mixture. This may be occurred through thymoquinone which is the major component of N.Sativa oil (Boulos, 1983). Thymoquinone has been found 
to inhibit lipid peroxidation (Nagi et al., 1999).

Chakravarty (1993) indicated that the use of N.Sativa seed oil leads to the fall of liver and heart enzymes activities denoting that N.Sativa. could protect liver parenchymal cells through its antioxidant properties or its mild inhibitory effect on oxidative energy metabolism.

Therefore, it is conceivable to assume that N.Sativa. may exert a protective role against amixture toxicity, since it was a meliorate all of these enzymes activities.

A significant decrease of total serum protein was recorded after treatment with the mixture of $\mathrm{NaNO}_{3}$ and S.S.Yellow for one month. The decrease of total serum protein due to the mixture treatment was reflected on serum albumin level where a remarkable decrease was recorded. It is clear that this decrease of albumin resulted from liver function impairment induced by the nitrite. The globulin fraction, on the other hand, was not affected generally through the same time, but it was affected after the recovery period and a mixture treatment lead to a decrease in globulin allover the experimental time and an increase in albumin/globulin ratio after the recovery period.

The harmful effect of nitrite is reflected on the biosynthesis of protein as reported by Yanni et al., (1991). They found that serum protein of rats are decreased due to the stimulatory effect of the nitrite on the function of both thyroid and adrenal glands which reported that sodium nitrite blocks protein synthesis while fast breakdown occurs. This leads to an increase of free amino acids and to a decrease of protein turnover. Furthermore, sodium nitrites have bean reported to produce retardation of growth (Atef et al., 1991), necrotic changes of liver and deterioration of the liver function and renal tubules (Anthony et al., 1994; ElBallal et al., 1994; Guler et al., 1994 and Rodriguez-Morona and Tarazona, 1994), reduction of myocardial GSHPX (Yang and Wang, 1991). Gastric and alteration of gastric mucosal absorption and decreased food consu mption (Bruning-Fann and Kaneene, 1993 and Hirose et al., 1993).

However, it is clear that sodium nitrite decrease total serum proteins and albumin mainly through its effects on liver either through inhibiting oxidative phosphorylation process and hence the availability of the energy source of protein synthesis (Anthony et al., 1994) and other metabolic processes or through the necrotic changes especially of plasma membrane (Guler et al., 1994). At the same time, the nitrite effects on the process of reabsorption in the kidney tubules and impaired absorption of digested food material cannot be ignored. Rodriguez-Morona and Tarazona (1994) indicated that uronyl nitrate decreases proximal tubular reabsorption which results in the activation of glomeular feed-back and lowers nephron filtration rate. Also, these results find good support of the study carried out by Helal et al. (2000) who illustrated a marked decrease of serum protein in rats after treatment with sunset yellow or carmine.

Furthermore, it is conceivable to assume that N.Sativa may exert a protective role against a mixtureinduced toxicity, Evidence of this view in the present findings is that N.Sativa treatment of a mixture-intoxicated rats resulted in an increase of total serum proteins. This effect is probably reflect the ability of N.Sativa to protect the protein manufacturing machinery from a mixture-induced cellular damage. 
In the present investigation, no significant changes occurred in the level of serum or tissues (examined) total lipids of rats treated with the mixture or mixture and N.Sativa for one month of treatment.

Similar results were obtained in case of serum triglycerides.Cholesterol is the most abundant steroid in the cells of higher animals. It is considered an essential structural component of cell membrane (Thorpe et al., 1964). In the present study, serum, brain, liver and heart cholesterol were increased signif icantly $(\mathrm{P}<0.01)$ over controls in the group treated with the mixture $\left(\mathrm{NaNO}_{3}\right.$, S.S.Yellow), while no significant changes were observed in rats treated with N.S in addition to the mixture.

Hanghton et al. (1995) demons trated that fixed oil and throquinone from N.S were used as inhibitors for membrane lipid peroxidation in ox, while the unsaturated fatty acids of N.Sativa may contribute antioxidant activity. The adverse effects of nitrate diet may occur in relation to peroxidation. This suggestion may support the findings of Bruning-Fann and Kaneene (1993) where, they found that nitrate ingestion in monogastric animals has been linked to interference with the metabolism of other antioxidants than N.Sativasuch as ascorbic acid, vitamin, A and E. Hence, the increased level of serum cholesterol noted herein in rats exposed to the mixture could be attributed to the peroxidation of cell membrane lipids (Standberg, 1977). So, a current evidence indicated that nitrites act as cell membrane oxidants. So, it could be mentioned the danger of extra serum cholesterol as a result of a mixture intake. It can be stored as a component of pathologic deposits in the arteries representing a potential risk for the development of atherosclerosis, thus increased the possibility of suffering from cardiovascular diseases and consequently hypertension.

Furthermore, hyper function of the thyroid gland manifested by higher levels of serum $T_{3}$ and $T_{4}$ in relation to controls after ingestion of mixture may be implicated with a future incidence of thyrotoxicosis.

From the present results, it must consequently be pointed out that most of the metabolic and pathological criteria in the subjected rats were altered by administration of this mixture followed by a recovery of many of them to normal status in days after their stoppage or as an effect of administration of N.Sativa.

The continuing world wide interest in toxicity/carcinogen city studies on the various edible food additives available will eventually unlimited information aiming towards the uninterrupted improvement of adverse effects whether behavioural or organic affecting mankind.

However, one should put into consideration the difficulty of extrapolation from animal studied to humans, moreover the difficulties in estimating human exposure to food additives.

Nevertheless, it is advisable to minimize the use of food additives in food and avoid using them as much as possible in infants and children foods.

\section{References}

1. Abdel-Rahim, E.A.; El-Desoky, G.E.; Shaban, O.A. and Afifi, A.S. (1988): Studies on the effect of sodium nitrite on hemoglobin fractions and growth rate of albino rats. Bull. Fac. Of Agric, Univ. of Cairo, 39(4): 1503-1516.

2. Abou EL-Zahab,H.S.H; EL-Khayat, Z.A.; Awadallah, R. and Mahdy, K.A. (1997) : Physiolog -ical effects of some synthetic food coloring additives 
on rats .Bull.Chem.Farm ., 136(10) ; 615-627.

3. Al-Awadi, F.; Fatania, H. and Shamte, U. (1991): The effect of plants mixture extract on liver gluconeog enesis in streptozotocin- induced diabetic rats. Diabetes Res., 18: 163168.

4. Al-Hader, A.; Aquel, M. and Hasan, Z. (1993): Hypoglycemic effects of the volatile oil of Nigella sativa seeds. Inter. Jour. of pharmacognosy, 31(2): 96-100.

5. Amerine, M.A.; Pangborn, R.M.; Rossler, E.B. (1965): Principles of Sensory Evaluation of Food. Academic Press, New York.

6. Anthony. M.L.; Gartland, K.P.; Beddell, C.R.; Lindon, J.K. (1994): Studies on the biochemical toxicology of uranyl nitrate in the rat. Arch. Toxicol., 68(1): 43-53.

7. Atef, M.; Abo-Norage, M.A.; Hanafy, M.S. and Agag, A.E. (1991): Pharmacotoxicological aspects of nitrate and nitrite in domestic fowls. Br. Poult. Sci., 32(2): 399-404.

8. Bartholonew, B. and Hill, M.J. (1984): The pharmacology of dietary nitrite and the origin of urinary nitrate. Fd. Chem. Toxic., 22:789.

9.Bellfield, A. and Goldberg, D.M. (1971): Hydrolysis of adenosinemonophosphate by acid phosphatase as measured by continuous spectroph otometric assay. Enzyme, 12:561.

10. Bilczuk, L., Gowin, A.; Ebertowska, Z. and Mach, H. (1991): Nitrate and nitrite levels in daily food rations of children from the rural pulowy regions. Rocz. Panstw.Zaki. Hig.42 (2):139-147

11. Boulos, L. (1983): Medicinal plants of North Africa Rreference. Publications, Algonac, M.I., pp. 108.

12. Brozelleca, J.F.; Olson, J.W. and Reno, F.G. (1989): Life time toxicity carcinogenicity study of FD \& $C$ red no. 40 (Allurared) in Sprague-Dawley rats. Fd. Chem. Toxic., 27(11): 701706.

13. Bruning-Fann, C.S. and Kaneene, J.B. (1993): The effect of nitrate, nitrite and $\mathrm{N}$-nitroso compounds on animal health Vet. Hum. Toxicol., 35(3): 237253.

14. Chakravarty, N. (1993): Inhibition of histamine release from mast cells by nigellon. Ann. Allergy. Mar., 70(3): 237-242.

15. Dini, L.; Bernardini, R.; Resti, M. and Viercei, A. (1992): Unusual reactions to food additives. Pedictr. Med. Chir., 14(1): 39-42.

16. Doran, G.R. and Wilkinson, J.H. (1975): The origin of the elevated activities of creatin kinase and other enzymes in the sera of patients with myxoedema. Clin. Chem. Acta., 62:203.

17. Doumas, B.T. (1975): Standards for total serum protein assays. A collaborative study. Clin. Chem., 21(8): 1159-1161.

18. Ebashi, S.; Toyo Kura, Y.; Momol, H. and Sugita, H. (1959): High creatine phosphokinase activity of serum of patients with progressive muscular dystrophy. J. Biochem. (Tokyo), 46:103.

19. El-Ballal, S.S.; Ezzo, O.H.; Shalaby, S.I.A. and Fawzy, Y. (1994): Sodium nitrite toxicity in Barki sheep. Egypt. J. of Comparative Pathology and Clinical Pathology. 7(2): 353-361.

20. El-Saadany, S.S. (1991): Biochemical effect of chocolate colouring and flavouring like substances on thyroid function and protein biosynthesis. Die Nahrung, 4: 335-43.

21. El-Sarha, A.J.; Hassan, H. Y. and Said, K.M. (1997): Haematobiochemical changes induced by oral administration of Nigella Sativa (black seed) to grats.

22. Fisk, C.H. and subbarow, M. (1925): The colorimetric determination of phosphorus. J. Biol. Chem. 66: 375383.

23. Fossati, P.and Medici, R. (1987): Abstract book: International Symposium on cholesterol control and radio vascular diseases: Prevention and Therapy. Milan. Italy.

24. Fujitani, T. (1993): Short-term effect of sodium benzoate in F344 rat and 
B6C3F, mice. Toxicol. Lett., 69(2): 171-179.

25. Ganong, W.F. (1997): Review of Medical Physiology. 8th ed. Libraure du liban, Appelton of longe, Lebanon, California, 296-311,

26. Gold. E. and Vladutin, A. (1994): Latrogenic hyperthyrodism of long duration in an individual with thyroxinbinding globulin deficiency. Clin. Chem., 40(12): 2323-2324.

27. Grant, D. and Bulter, W. H. (1989): Chronic toxicity of sodium nitrite in male rats.Fed .Chem.Toxic., 27(9): 565- 571.

28. Greenbalt ,M.and Mirvish,S.S.(1972) Dose-Respons Studies with concurrent administration of piperazine and sodium nitriteto mice .J.Nat.Cancer Inter., 49 : 119-124.

29. Guler, A.H.; Sapan, N.; Ediz, B.; Genc, Z. and Ozkan, K. (1994): Effect of copper on liver and bone metabolism in malnutrition. Turkish, J. Pediat. 36(3): 205-213.

30. Guyton, A.C. and Hall, J.E. (1998): Text book of medical physiology. 9th ed. WB. Saunders Company, Philadelphia, London, Toronto, Sydney, Tokyo, 945-956.

31. Harley, J.D. and Robin, H.C. (1962): The effect of the nitrite ion on intact human erythrocytes. Blood, 20(6): 710713.

32. Harper, F.A. (1977): Review of physiological chemistry long medical publication, less Altes, California, 15 th ed. Pp: 326-379.

33. Harris, J.B. (1986): Natural toxins. Animal, plant and microbial. Cited in food and additives in tolerance in childhood (1994). P. 179. Black well scientific London-Boston.

34. Harrison, D.G. and Bates, J.N. (1993): The nitrovassodilators: new ideas about old drugs. Circulation, 87: 1461.

35. Hedaya, S.A. (1995): Effect of Nigella sativa seeds (black seeds) extract on some haematological and biochemical parameters in rats. Alexandria, J. Veter, Sciena, 11: 95-99.
36. Heisler, E.G.; Siciliano, J.; Krulick, S.; Feinberg, J. and Schwartz, J.H. (1974): Changes in nitrate and nitrite content and search for nitrosamines in storage, A bused spinach and beets. J. Agric. Food Chem., 22(6): 1029-1032.

37. Helal, E.G.E. (2001): The protective role of Royal Jelly against sodium nitrite and sun-set yellow toxicity in albino rats. The Egyptian Journal of Hospital Medicine , 2: 121-137.

38. Helal, E.G.E.; Zaahkouk, S.A. and Mekawy, H.A. (2000): Effect of some food colours (synthetic and natural products) on liver and kidney functions of young albino rats. The Egyptian Journal of Hospital Medicine, 103:131.

39. Hirose, M.; Tanaka, H.; Takashi, S.; Fulakuchi, M.; Fakushima, S. and Ito, N. (1993): Effects of sodium nitrite and catechol, 3-methoxy catechol, or butylated hydroxyanisole in comb ination in rat multiorgan carcinogenesis model. Cancer Res., 53: 32-37.

40. HMSO. (Her Majesty's Stationary Office, London). (1987): Food additives. The balanced approach. Cited in food additives intolerance in childhood (1994)p. 180. Black well scientific. London-Boston.

41. Houghton, P.J.; Zarka, R.; De-lasHeras, B. and Hoult, J.R. (1995): Fixed oil of Nigella sativa and derived Thymoquinone inhibit eicosanoid generation in leukocytes and membrane lipid peroxidation. Plasta. Med. Feb., 61(1): 33-36.

42. Katzung, B.G. (1995): Basic and clinical pharmacology. A long medical book, 6th ed., less Altes, California, pp: 199-203.

43. Khanna, T.; Zaidi, F.A. and Dandiya, P.C (1993): CAN and analgesic studies on Nigella sativa. Fitoterapia, 64: 5, 407-410.

44. Knight, J.A.; Anderson, S. and Rawle, J.M. (1972): Chemical basis of the sulfo-phosphovanillin reaction for estimation total serum lipids. Clin. Chem., 18(3): 199-202.

45. Lindsay, R.C (1985): Food additives in Fennema. Cited in: Food and Food additives intolerance in child hood. P. 
179. Ed: David, T.J. Black well scientific. London-Boston.

46. London, W.T.; Henderson, W. and Cross, R.F. (1967): An attempt to produce chronic nitrite toxicosis in swince. J.A.V.M.A., 150(4): 398-402.

47. Maekawa, A;Ogin, T;O nedera, H; Furata, K; Matsuoka,C; Ohno,Y.and Odoshima,S.(1982): Carcinogenicity studies of sodium nitrite and sodium nitrate in rats.Fd.Chem.Toxic., 20: 2533.

48. Meister, A.; Tate, S.S. and Groffith, O.W. (1981): Gamma-glutamyl transpeptidase. Method Enzymil., 77: 237-253.

49. Morliere, P.; Moysan. A.; Santus, R.; Huppe; J.C. and Dubertret, L. (1991): $\quad$ UVA-induced lipid peroxidation in cultured human fibroblasts. Biochem. Biophys. Acta 1084: 261-268.

50. Nagi, M.N.; Alam, K.; Badary, O.A.; Al-Shabanah, O.A.; Al-Sawaf, H.A. and Al-Bekairi, A.M. (1999): Thymoquinone protects against carbon tetrachloride hepatotoxicity in mice via an antioxidant mechanism. Biochem. Mol. Biol. Int., 47(1): 153-159.

51. Osman, M.A.; Afifi, A.; Hussien, R.M.; Kamilia, B.; Abdel-Aziz and Salah, S.H. (1995): Long-term biochemical and genotoxicity studies of four synthetic food and drug colorants in mice. Bull. Fac. Pharm. (Cairo Univ.), 33(1): 13-21.

52. Raabo, E. (1963): Determination of serum lactic dehydrogenase by the tetrazolium salt method. Scand. J. Clin. and Lab. Invest., 15:233.

53. Rastogi, P.B. and Prasad, O.M. (1983a): Haematological changes induced by feeding a common food colour material yellow in albino mice. Toxicol. Lett., 16: 103-108.

54. Rastogi, P.B. and Prasad, O.M. (1983b): Haematological abnormalities induced by pre feeding a common food colour metanil yellow in mice. Proc. Natl. Acad. Sci. India Sec. B., 53(1): 110.

55. Ray Sarkar, B.C. and Chauhan, U.P.S. (1967): A new method for determining microquantities of calcium in biological materilas. Anal. Biochem., 20: 155-166.

56. Reitman, S. and Frankel, S. (1975): A colourimetric method for the determination of serum glutamic oxaloacetic and glutamic pyrovic transaminases. Am. J. Clin. Path., 28: 56.

57. Reutov, V.P.; Sorokina, E.G.; Pinelis, V.G.; Korshunova, T. S.; Rodionov, A.A.; Koshelev, V.B.; Strukova, S.M.; Kaiushin, L.P.; Braquet, P. and Komissarova, L.K.H. (1993): The compensatory-adaptive mechanisms in nitrite-induced hypoxia in rats. Bull. Eksp. Biol. Med., 116(11): 506-508.

58. Rodak, F.P. (1995): Routin laboratory evaluation of blood cells and bone marrow. In: Diagnostic hematology, pp.: 125-129, W.B. Saunders Comp. Phild. London, Toronto, Montreal, Sydney, Tokyo.

59. Rodriguez-Morona, P.A. and Tarazona, J.N. (1994): Nitrite-induced methemoglobin formation and recovery in rainbow trout at high chloride concentrations. Bull. Environ. Contain. Toxicol. 53(1): 113-139.

60. Rojkin, M.L.; Olguin. D.E.; Mariani, M.C.; Drappo, G.A.Y. and Sosa, C.P. (1974): Protein as totales del sureo: causes mas Frecuentes de error en la roaccion del Biuret Nuevo reactive cupraol calino estable. Biog. Del. Atlantico, V. 1163-1193.

61. Rybczynska, M.; Hoffmann, S. and Goslar, J. (1996): Molecular changes in erythrocyte membranes induced by nitroimidazoles and radiation. Pol. J. Pharmacol., 48: 269-280.

62. Salomi, M.J.; Nair, B.C. and panikkar, K.R. (1991): Inhibitory effects of Nigella sativa and saffron (Crocus sativus) on chemical carcino genesis in mice. Nutrition and Cancer, 11(1): 67-72.

63. Salomi, M.J.; Nair, S.C.; Jayaivardhanan, K.K.; Varghesa, C.D. and panikkar, K.R. (1992): Antitumor principles from Nigella sativa seeds. Cancer. Lett. 1992. Mar. 31; 63(1): 41-46. 
64. Sharma, S.D. (1989): Renal gross biochemistry of albino rat influenced by a common food color, Metanil yellow. J. Adv. Zool., 10(2): 95-98.

65. Shelpov, V.; Chekulaev, V. and Pasha-Zade, G. (1991): Factors within the body determining the glycogen reserves in the tissues of rats. Biomed. Sci., 2(2): 111-120.

66. Siest, G. and Schielf, M.J. (1981): Interpretation Des Examens De laboratoire, Karger ed., pp.: 206-223.

67. Smith, R.P. (1991): Chemicals reacting with various forms of hemoglobin: biological significance, mechanisms and determination. J. Forensic Sci., 36(3): 662-672.

68. Sokal, R.R. and Rohif, F.J. (1981): Biometry: The principles and practice of statistics in biological research. 2nd ed. Freeman, W.H. Company San. Francisco.

69. Stanberg. (1977) : Nitrate and nitrite suplly and metabolism in man .Nutr. Abs. Revs.Ser (A) , 47:1119-1123.

70. Tietz, N.W. (1986): Text book of clinical chemistry, W.B. Saunders Co., London, Philadelphia.

71. Til,H.P; Falke, H.E; Kuper ,C.F. and William, M.I. (1988): Evaluation of the oral toxicity of potasium nitrite in a 13 week driking water study in rats. Fd.chem.Toxic., 26(10) : 851-859.

72. Thorpe, W.V.; Bary , H.G. and James .S.P.(1964): Biochemistry for medical students 8 th Ed.J.and Achuchill LTD,London,pp.80.

73. Van Kampen, E.J. \& Zulstra, W.G. (1961): Standerdization of hemoglo - binometr: The hemoglobin cyanide method. Clin. Chem. Acta.: 538-540b.

74. Walker, B.S.; Boyd, W.C. and Asimov, I. (1957): Biochemistry and human metabolism. Williams \& Wilkins-Baltimore, New York.

75. Webster, D. (1977): Albumin standards and measurement of serum albumin with bromochresol green. Clin. Chem., 23: 663-666.

76. Whitby, L.G.; Smith, A.F.; Beckell, G.J. and Waker, S.W. (1992): Liver diseases "In Lecture Notes on Clinical Biochemistry". Blackwell scientific publication. 5th edition.

77. White, J.W. (1975): Relative significance of dietary sources of nitrate and nitrites. J. Agric. Food chem.., 2(5): 886-891.

78. Whitley, R.J.; Meikle, A.W.; Watts, N.B. (1996): Endocrinology. In: Tietz N.W. Fundamentals of clinical chemistry. W.B. Saunders Company, Philadelphia, London, Toronto, 673704.

79. Yanni, M.; Abdel-Dayem, S.M. and Abdel-Azim, B.H. (1991): Biochemical and Histological changes due to preservatives in rats. Egypt. J. Histol., 14(2): 431-440.

80. Yoshida, Y.; Hirose, M.; Takaba, K.; Kinura, J. and Ito, N. (1994): Induction and promotion of forestomach tumors by sodium nitrite in combination with ascorbic acid or sodium ascorbate in rats with or without N-methyl-N-nitro-N-nitrosog uanidine pretreatment. Int. J. Cancer, 56: $124-128$. 


\section{الدور الوقائى لحبة البركة ضد التفاعل الناتج بين نترات الصوديوم

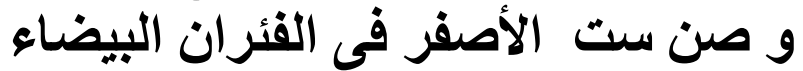

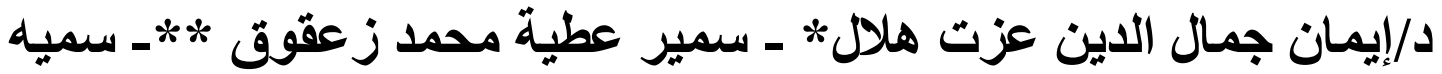

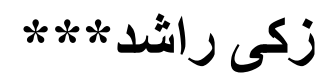

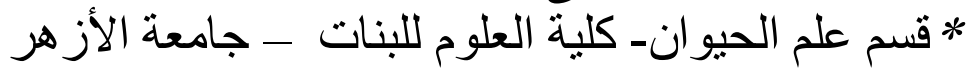

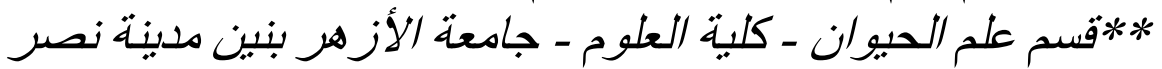

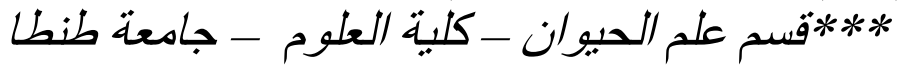

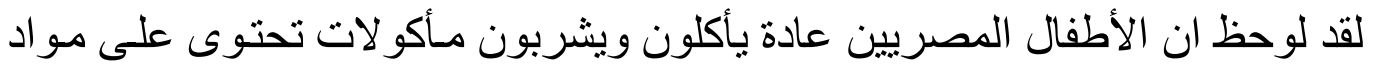

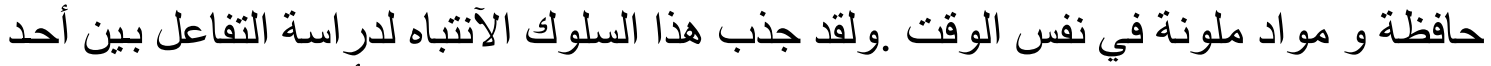

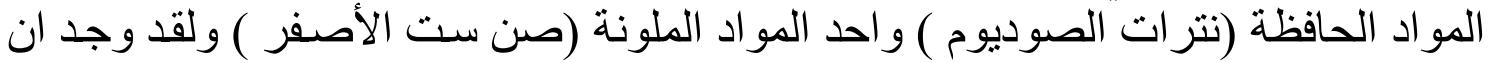
خلط النسبة المسموحة لكلا من هاتين المادتين قد ادى الى الى جر عة مميتة لذلك تم التم استخدام

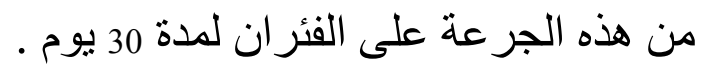

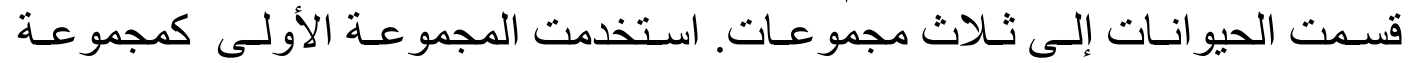

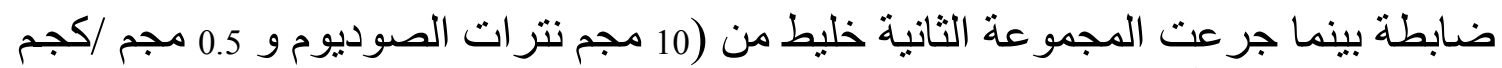

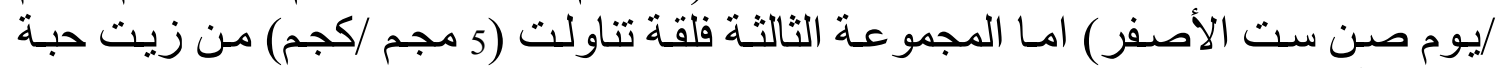

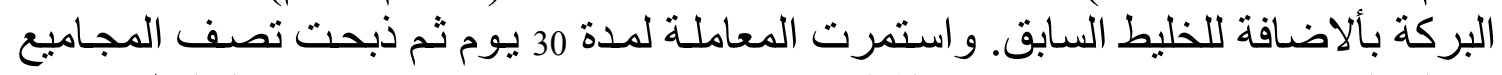

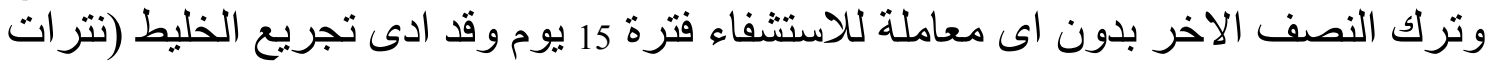

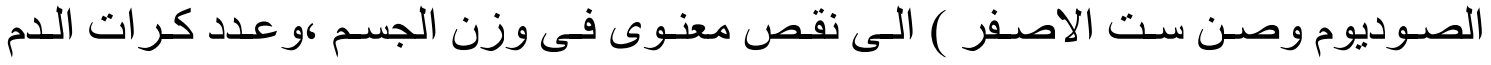

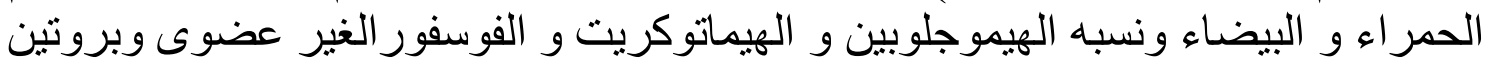

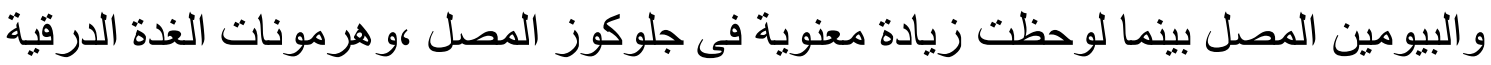

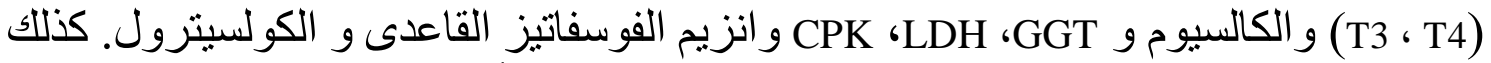

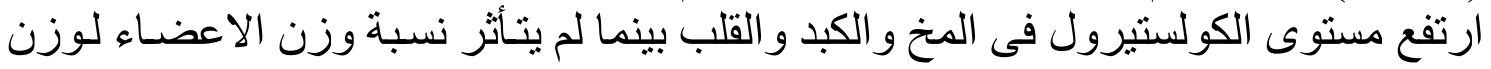

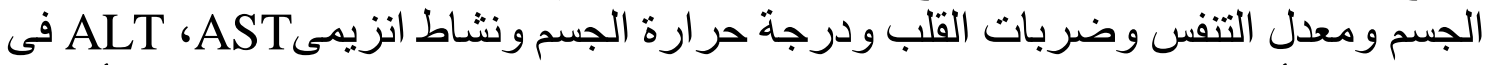

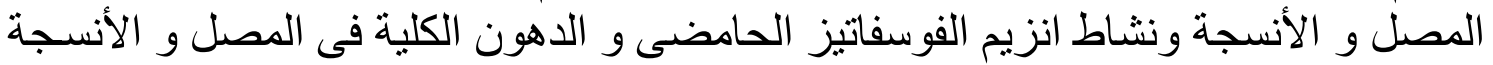

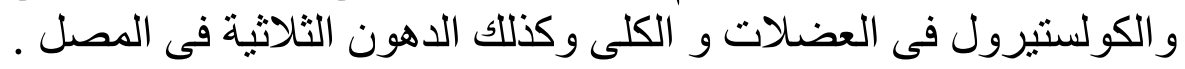

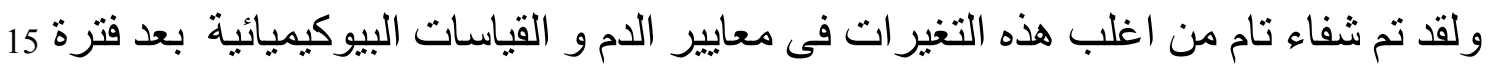

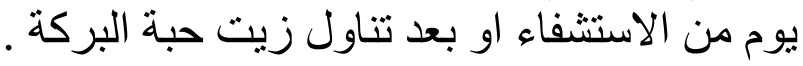

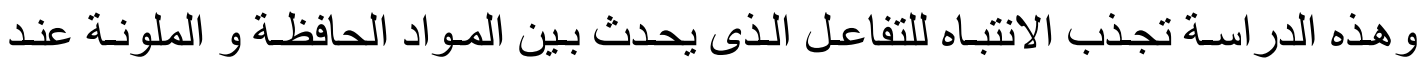

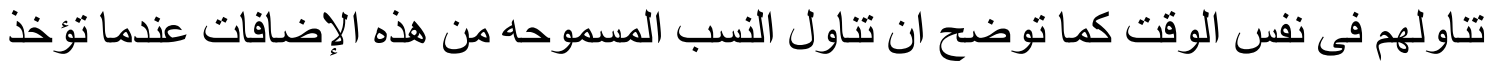

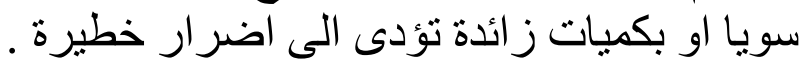

